\title{
Effect of daily intake of heat-killed Lactobacillus plantarum HOKKAIDO on immunocompetence: A randomized, double-blind, placebo-controlled, parallel-group study
}

\author{
Akane Haseda', Mie Nishimura', Miwako Sugawara ${ }^{2}$, Masafumi Kudo ${ }^{2}$, Ryoji Nakagawa ${ }^{2}$, \\ and Jun Nishihira,"*
}

${ }^{1}$ Health Information Science Research Center, Hokkaido Information University, Ebetsu, Hokkaido 069-8585, Japan; ${ }^{2}$ Northern Advancement Center for Science \& Technology, Sapporo, Hokkaido 001-0021, Japan; ${ }^{3}$ FoodProcessing Research Center, Hokkaido Research Organization, Ebetsu, Hokkaido 069-0836, Japan

"Corresponding author: Jun Nishihira, M.D., Ph.D., Health Information Science Research Center/Department of Medical Management and Informatics, Hokkaido Information University, Nishi Nopporo 59-2, Ebetsu, Hokkaido 069-8585, Japan

Submission Date: February $9^{\text {th }}$, 2019; Acceptance Date: March 27 ${ }^{\text {th }}$, 2020; Publication Date: March $30^{\text {th }}, 2020$

Citation: Haseda A., Nishimura M., Sugawara M., Kudo M., Nakagawa R., Nishihira J Effect of daily intake of heat-killed Lactobacillus plantarum HOKKAIDO on immunocompetence: A randomized, double-blind, placebo-controlled, parallel-group study. Bioactive Compounds in Health and Disease 2020; 3(3): 32-54. DOI: https://doi.org/10.31989/bchd.v3i3.697

\begin{abstract}
Background: Consumption of Lactobacillus plantarum HOKKAIDO (HOKKAIDO strain) reportedly increases immunocompetence. However, the concentration of viable bacteria and the type of food they can be incorporated into limits their consumption. The study aims to demonstrate the effect of daily intake of the heat-killed L. plantarum HOKKAIDO strain (HK-HOKKAIDO strain; $5 \times 10^{10}$ colony-forming units/day) by healthy subjects with low natural killer (NK) cell activity for 8 weeks.
\end{abstract}

Method: In this randomized, double-blind, placebo-controlled, parallel-group study, 70 healthy Japanese subjects who showed relatively low NK cell activity were recruited and randomly assigned to the HK-HOKKAIDO strain or placebo group. All subjects ingested one capsule per 
day for 8 weeks. We conducted medical interviews and performed body composition measurements, vital sign examinations, and blood sampling at weeks 0 (baseline), 4, and 8, and we collected salivary samples at weeks 0 and 8 . In addition, the frequency and severity of cold symptoms in the subjects were recorded daily during the intake period.

Results: Intake of the HK-HOKKAIDO strain did not increase the NK cell activity or immunity marker levels, including those of immunoglobulin, leukocyte fraction, and salivary secretory immunoglobulin A. However, the frequency and severity of the common cold symptoms were significantly reduced after the daily consumption of the HK-HOKKAIDO strain.

Conclusions: The results showed that HK-HOKKAIDO strain administration can decrease the frequency and severity of common cold symptoms in healthy subjects. Our findings support the use of the HK-HOKKAIDO strain as a functional food with health benefits.

\section{Clinical trial registration: UMIN000034822}

\section{BACKGROUND}

The intestinal flora consists of a large number of resident bacteria [1,2] and this flora is indicative of the health of the host with respect to the immune function [3]; therefore, maintaining the balance of various kinds of bacteria in the intestine is important. However, Japanese individuals in this modern era have reported an imbalance in their intestinal flora due to the adaptation of Western diet habits, thereby leading to a decline in their immune function [4]. The immune system comprises two classes: innate immunity, which is a natural nonspecific defense mechanism against infections, and acquired immunity, which is induced by antigen stimulation after birth. Natural killer (NK) cells are the key factors of the innate immunity and various factors, such as mental stress [5,6] and smoking [7,8], can decrease NK cell activity. Several reports have suggested that the promotion of NK cell activity was related to the inhibition of influenza infection [9-11]. Therefore, the development of functional foods that can activate NK cells is important for maintaining the function of the immune system.

Lactic acid bacteria reportedly cause NK cell activation $[12,13]$ by inducing the production of cytokines such as IL-12, which exhibits NK cell activation effects. Phagocytosis is enhanced during colonization by lactic acid bacteria. Plant lactic acid bacteria, which are often found in fermented foods such as pickles, were previously considered to be non-functional in humans because they cannot settle in the human intestine; however, recent studies have shown a high occurrence rate of these bacteria in the human intestines of vegetarians [14], and these bacteria 
have been shown to be effective in cancer suppression [15]. In addition, plant lactic acid bacteria can survive, even in harsh conditions such as high-salt environments or low-pH environments as well as in the presence of tannins, owing to their tannin-resistant peptidoglycan cell wall containing diaminopimelate [16].

The HOKKAIDO strain of lactic acid bacteria was isolated from pickled vegetables from the Hokkaido Research Organization. Previous in vitro and in vivo studies have shown that HOKKAIDO strains are resistant to salt, alcohol, and $\mathrm{pH}$; further, they can protect against foodpoisoning infections and enhance the absorption of isoflavones in the intestinal tract [17]. A study showed that the HOKKAIDO strain increased the IL-12 mRNA expression level in human dendritic cells [18]. In addition, a previous clinical study in subjects aged $<50$ years showed that the daily consumption of yogurt containing the HOKKAIDO strain for 56 days significantly increased the NK cell activity compared with the NK cell activity of a placebo food group [19]. These facts suggest that the regular and consistent consumption of the HOKKAIDO strain increases immunocompetence.

However, there is a restriction in the number of viable bacteria that can be consumed or the type of foods that these viable bacteria can be incorporated into considering the quality control measures that should be maintained in food production. Therefore, the Northern Advancement Center for Science \& Technology, a supplier of test food materials, produced the "Heat-Killed Lactobacillus plantarum HOKKAIDO (HK-HOKKAIDO strain)." This strain was more stable than the other viable probiotics; therefore, high concentrations of these bacteria can be added to foods, and a wide range of foods can be used for the incorporation of these bacteria.

This randomized, double-blind, placebo-controlled, parallel-group study aims to evaluate the effects of the intake of the HK-HOKKAIDO strain on immunocompetence in healthy subjects with relatively low NK cell activity.

\section{METHODS}

\section{Study design}

This placebo-controlled, randomized, double-blind, parallel-group comparative study was conducted over a period of 8 weeks. Data were collected between November 2018 and February 2019 at the Hokkaido Information University, Health Information Science Center (Ebetsu, Hokkaido, Japan). The schedule of the trial is summarized in Table 1.

Interviews were conducted by a research doctor and a research nurse to obtain the medical information. They analyzed the vital signs, performed body composition measurements and blood sampling, and administered the visual analog scale (VAS) questionnaire in the second (week 0, baseline), third (week 4), and fourth (week 8) visits. Salivary samples were collected at the second 
and fourth visits. In addition, the frequency and severity of the common cold symptoms in the subjects were recorded by subjects themselves during the intake period.

The subjects ingested one capsule (an HK-HOKKAIDO strain capsule or a placebo capsule) daily for 8 weeks. During the entire study period, the subjects were instructed to continue their daily activities, including food consumption and exercise habits, as before; however, they were instructed to avoid any supplements and foods containing lactic acid bacteria, including the HOKKAIDO strain. The subjects used a diary to record their daily activities, which was reviewed by a medical doctor or a nurse at each visit.

The primary outcome was a change in the NK cell activity. The secondary outcomes included differences in immunoglobulin [immunoglobulin A (IgA), immunoglobulin G (IgG), and immunoglobulin M (IgM)] levels, leukocyte fraction (neutrophils, lymphocytes, monocytes, eosinophils, basophils, and neutrophil-lymphocyte ratio), and salivary secretory $\operatorname{IgA}(\mathrm{s}-\operatorname{IgA})$ levels. The VAS questionnaire was administered to assess defecation and fatigue, along with the frequency/severity of the common cold symptoms.

Table 1: Schedule of the clinical trial

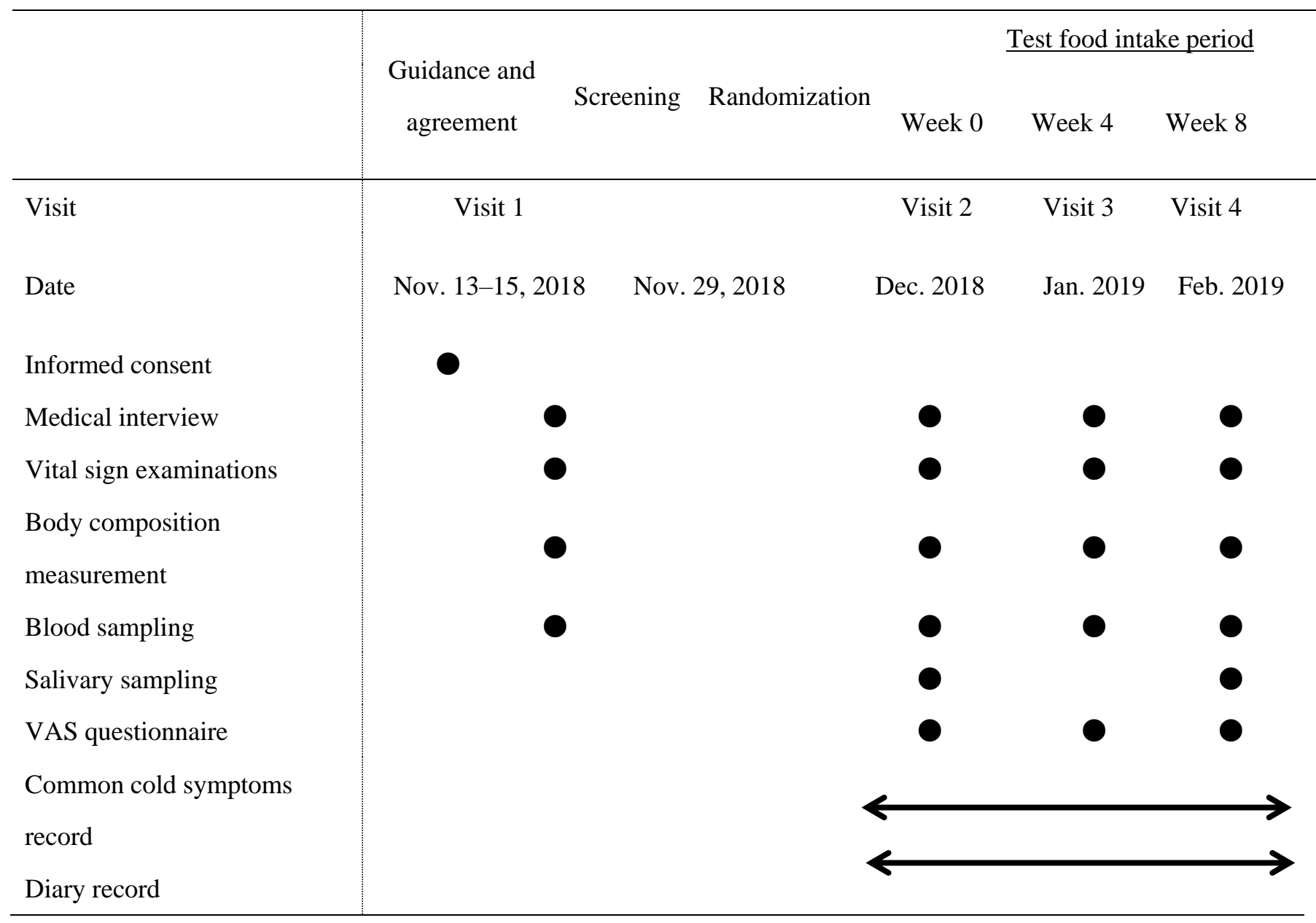

•: conducted. 


\section{Ethical approval}

The current clinical trial was conducted in compliance with the ethical guidelines on medical research in humans (the Ministry of Education, Culture, Sports, Science and Technology and the Ministry of Health, Labor and Welfare) and the Helsinki Declaration (revised by the Fortaleza General Meeting of the World Medical Association). The trial protocol was approved by the ethics committee of the Hokkaido Information University (Ebetsu, Hokkaido, Japan; approved on September 25, 2018; approval number: 2018-15). This trial was registered at www.umin.ac.jp/ctr/index.htm (registered on November 9, 2018; registration number: UMIN000034822).

\section{Study subjects}

We screened 134 volunteers on their first visit, and all of them provided written informed consent to participate in the study. During the screening test, we conducted medical interviews and performed vital sign examinations, body composition measurements, and blood sampling including the determination of NK cell activity. After screening, 70 healthy Japanese subjects who showed relatively low NK cell activity were enrolled in the study. The inclusion and exclusion criteria are summarized in Table 2.

The 70 healthy Japanese subjects enrolled were randomly assigned to the HK-HOKKAIDO strain or placebo group. The methods of assignment and blinding are briefly described below. The Northern Advancement Center for Science \& Technology, which provided the test foods, assigned the identification food numbers either the HK-HOKKAIDO strain capsule or the placebo capsule and were then printed on the food packaging. Identification of the food number information was strictly sealed and transferred to a third-party data center, independent of the study (Media Educational Center, Hokkaido Institute of Information Technology, Ebetsu, Hokkaido, Japan). The eligible subjects were randomly assigned to the HK-HOKKAIDO strain or placebo groups, which were stratified by sex, age, and NK cell activity at the first visit. Assignments were computergenerated on the basis of stratified block randomization at a third-party data center, and the block size was 36. The research collaborators at the Hokkaido Information University, including medical doctors, nurses, clinical research coordinators, and statistical analysts were blinded to the identification of the food numbers and the assignment information during the trial period. The identification of the food numbers and assignment information were disclosed only after all the analytical data were collected; the subjects included in the efficacy analysis were identified and the methods of statistical analyses were finalized. 
Table 2: Inclusion and exclusion criteria

Inclusion 1 . Age $\geq 30$ years and $<50$ years

criteria $\quad 2$. Subjects who show relatively low NK cell activity $(<70 \%)$

1. Subjects with serious diseases and/or infections

2. Subjects with a major surgical history relevant to the digestive system, such as gastrectomy, gastrorrhaphy, and enterectomy

3. Subjects with unusually high and/or low blood pressure and/or abnormal hematological data

4. Subjects with severe anemia

5. Pre- or postmenopausal women with complaints of obvious physical changes

6. Subjects who are at risk of having allergic reactions to drugs or foods

7. Subjects who regularly ingest products containing the HOKKAIDO strain.

8. Subjects who regularly take medicines, functional foods, and/or supplements that

Exclusion would affect the immune function

criteria 9. Heavy smokers, alcohol addicts, or subjects with a disordered lifestyle

10. Subjects who donated either $400 \mathrm{~mL}$ whole blood within the last 16 weeks (women) or 12 weeks (men), $200 \mathrm{~mL}$ whole blood within the last 4 weeks (men and women), or blood components within the last 2 weeks (men and women), prior to the current study

11. Pregnant or lactating women or women who expect to be pregnant during this study

12. Subjects who are currently participating in other clinical trials or participated within the last 4 weeks prior to the current study.

13. Any other medical and/or health reasons unfavorable to participation in the current study, as judged by the principal investigator

\section{Sample size}

The sample size was statistically determined to obtain a power of $80 \%$ and a two-sided significance level of 5\%. Based on the data of the previous clinical trial of the HOKKAIDO strain [19], to demonstrate a difference in the NK cell activity at week 8, which was postulated to have an intergroup difference of $7.5 \%$ with a standard deviation of $10 \%$, a sample size of 60 (30 in each group) was required. Assuming a 15\% loss in the follow-up rate, 70 subjects (35 in each group) were enrolled. 


\section{Preparation of the test food}

The HK-HOKKAIDO strain capsules and placebo capsules were provided by the Northern Advancement Center for Science \& Technology. Approximately $230 \mathrm{mg}$ of the powder containing $5 \times 10^{10}$ colony-forming units (CFUs) of the HK-HOKKAIDO strain was encapsulated in a white gelatin capsule. The nutrient compositions of the HK-HOKKAIDO strain capsule and placebo capsule are presented in Table 3 . The HK-HOKKAIDO strain counts were analyzed using the 4',6diamidino-2-phenylindole staining method. Nutrient composition analyses were performed at the Japan Food Research Laboratories (Hokkaido, Japan). The placebo capsule contained dextrin instead of the HK-HOKKAIDO strain. The HK-HOKKAIDO strain and placebo capsules were identical in appearance.

Table 3: Nutrient composition of the HK-HOKKAIDO strain and placebo capsules per day

\begin{tabular}{|c|c|c|c|}
\hline Nutrients & Unit & $\begin{array}{l}\text { Heat-killed } \\
\text { HOKKAIDO strain }\end{array}$ & Placebo \\
\hline Calories & kcal & 1.11 & 1.11 \\
\hline Proteins & $\mathrm{g}$ & 0.08 & 0.06 \\
\hline Lipids & $\mathrm{g}$ & 0.00 & 0.00 \\
\hline Carbohydrates & $\mathrm{g}$ & 0.18 & 0.20 \\
\hline Sodium chloride & g & 0.40 & 0.03 \\
\hline Heat-Killed Lactobacillus plantarum HOKKAIDO & $\mathrm{CFU}$ & $5 \times 10^{10}$ & - \\
\hline
\end{tabular}

\section{Physical, hematological, biological, and salivary assessments}

Blood was collected from the subjects after a 12-h fast and used for the following hematological examinations: white blood cell (WBC), red blood cell (RBC), and platelet (Plt) counts; hemoglobin $(\mathrm{Hb})$ and hematocrit $(\mathrm{Ht})$ levels; and neutrophil, lymphocyte, monocyte, eosinophil, and basophil concentrations. The biological examinations included the following: liver function tests [aspartate aminotransferase (AST), alanine aminotransferase (ALT), $\gamma$-glutamyltranspeptidase ( $\gamma$-GTP), alanine phosphatase (ALP), and lactate dehydrogenase (LDH)]; renal function tests [blood urea nitrogen (BUN), creatinine (CRE), and uric acid (UA)]; lipid profile [total cholesterol (TC), lowdensity lipoprotein cholesterol (LDL-C), high-density lipoprotein cholesterol (HDL-C), and triglyceride (TG)]; blood glucose profile [fasting plasma glucose (FPG) and hemoglobin $\mathrm{A}_{1 \mathrm{c}}$ $\left(\mathrm{HbA}_{1 \mathrm{c}}\right)$ ]; and immunoglobulin levels (IgA, IgG, and IgM).

Chromium-51 $\left({ }^{51} \mathrm{Cr}\right)$ release assays were used to measure NK cell activity at visit $1-4$. Target 
cells were labeled with ${ }^{51} \mathrm{Cr}$, following which, the label was released from the target cells by cytolysis. After centrifugation, the supernatants were directly analyzed using a gamma counter.

Saliva was collected using a Salivette ${ }^{\circledR}$ Cotton Swab (Sarstedt K.K., Tokyo, Japan). The subjects were instructed to chew the swab for $60 \mathrm{~s}$ to stimulate salivation, following which the saliva was collected from the swab by centrifugation (3000 rpm $\times 5 \mathrm{~min})$. Enzyme immunometric assays were used to assess salivary s-IgA levels.

Hematological examinations were performed using the XN-1000 hematology analyzer and an automatic blood cell counter and liver function tests were performed using the Japanese Society of Clinical Chemistry standardization method. For the renal function tests, BUN, UA, and CRE were measured using the urease/glutamate dehydrogenase, uricase-peroxidase, and enzymatic methods, respectively. For the lipid profile, TC, LDL-C, HDL-C, and TG were measured using the cholesterol oxidase, selective solubilization, selective suppression, and free glycerol elimination methods, respectively. For the blood glucose profile, FPG and $\mathrm{HbA}_{1 \mathrm{c}}$ were measured using the hexokinase and latex aggregation methods, respectively. Immunoglobulins were measured using turbidimetric immunoassay.

Blood tests including those for NK cell activity and salivary s-IgA level were performed at Sapporo Clinical Laboratory, Inc. (Hokkaido, Japan). The body composition [body fat rate (BFR) and body mass index (BMI)], blood pressure, and body temperature were measured using the body composition analyzer DC-320 (Tanita Corp., Tokyo, Japan), automatic blood pressure monitor HEM-7080IC (Omron Co., Ltd., Kyoto, Japan), and electronic thermometer C231 (Terumo Corporation, Tokyo, Japan), respectively.

\section{VAS questionnaires assessing defecation and fatigue}

The subjects completed a VAS questionnaire for the evaluation of the effects of the HKHOKKAIDO strain on defecation and fatigue. The subjects were instructed to place an " $\mathrm{X}$ " along a $100-\mathrm{mm}$ line to provide a rating from the worst to the best condition for the question assessing fatigue based on their current health condition. The left end of the line $(0 \mathrm{~mm})$ was defined as the worst condition and the right end $(100 \mathrm{~mm})$ was defined as the best condition. The questionnaire results were assessed by evaluating the length from the beginning of the line on the left to the "X." An increase in the VAS score indicated a reduction in fatigue. 


\section{Evaluation of common cold symptoms}

The subjects recorded their common cold symptoms daily in a diary during the intake period. The symptoms of common cold included general symptoms (fever, chills, and malaise) and respiratory symptoms (coughing, sputum production, sore throat, nasal discharge, nasal congestion, and sneezing). The subjects rated the severity of the symptoms on a scale from 1 to 5 (1= nothing; 2 = slightly mild symptoms; 3 = mild symptoms; 4 = slightly strong symptoms; 5 = very strong symptoms). We aggregated the severity into three categories as follows: "1 = nothing" was categorized as "no symptoms," "2 = slightly mild symptoms" and " 3 = mild symptoms" were categorized as "mild," and " $4=$ slightly strong symptoms" and " 5 = very strong symptoms" were categorized as "severe." The response number for each intake group was summarized every 4 weeks, from day 0 to day 28 and from day 29 to day 58. In addition, the response rate was calculated using the following equation:

$$
\text { Response rate }(\%)=\frac{\text { Number of responses for each criterion }}{\text { Number of participants } \times 28 \text { (days) }} \times 100
$$

In addition, we determined the number of subjects with common cold symptoms ( $>10$ episodes) during the study period [20]. The number of participants for each group was summarized every 4 weeks, from day 0 to day 28 and from day 29 to day 58.

\section{Assessment of safety}

We further assessed the incidence of unfavorable symptoms and findings as well as the abnormal changes in the laboratory variables as adverse events. The severity of the adverse events and their relationship with the test food were classified according to the protocol criteria established by the investigator. Laboratory variables on the safety outcomes were assessed according to the guidelines on the criteria for side effects defined by the Japanese Society of Chemotherapy [21], and the excluded anomaly levels were defined by the investigator. All adverse events were reported as follows: symptoms, occurrence date, and severity (mild/moderate/severe); relation to the test food (not relevant/probably not relevant/probably relevant/relevant/not assessable); continuation or discontinuation; treatment; and outcome (day). Adverse events were monitored during the intervention period of 8 weeks.

\section{Statistical analysis}

Student's $t$-tests were performed to analyze the primary, secondary, and safety outcomes by 
comparing the changes in the values at baseline to those at week 4 and/or week 8 between the two subject groups. To assess the frequency and number of subjects with common cold symptoms, the chi-squared test was used for the analysis by comparing the response number of each severity in the first intake period (day 0 to day 28) and the last intake period (day 29 to day 56) between the two subject groups. If the chi-squared $p$-value was $<0.05$ between the two groups, we performed a post hoc analysis (adjusted residual). For subject characteristics, Fisher's exact probability test was used for sex and the Mann-Whitney $U$ test was used for the intake rate; Student's $t$-tests were used for other subject characteristics. All statistical analyses were performed using SPSS version 25.0 (IBM Japan, Ltd., Tokyo, Japan), and $p$-values of $<0.05$ were considered statistically significant. In the present study, multiplicity of the statistical analyses was not considered, although multiple items and multiple time points were evaluated.

\section{RESULTS}

\section{Subject dropouts and characteristics}

The flow of the trial is presented in Fig. 1. Subjects who provided informed consent $(n=134)$ were assessed for eligibility, and 70 subjects were enrolled in the present study. All enrolled subjects were randomized into one of the two intervention groups (placebo group, $n=35$; HKHOKKAIDO strain group, $n=35$ ). Three subjects dropped out for personal reasons before the trial started, one subject withdrew because of elevated liver function markers at week 0 (before the intake of the test food), one subject withdrew because of an onset of sudden deafness, and one subject dropped out for personal reasons. Finally, 64 subjects completed this trial: 34 in the active test food group and 30 in the placebo group. Furthermore, 67 subjects, excluding the 3 who dropped out before trial commencement, were included in the safety analysis. We excluded 6 participants with drop-out and 3 subjects with compliance violation from the efficacy analysis; finally, we included 32 subjects in the HK-HOKKAIDO strain group and 29 in the placebo group. In addition, 3 subjects were excluded from the analysis of the frequency of common cold symptoms because they were suspected to have allergic rhinitis or empyema.

The sex ratio, mean age, BFR, BMI, NK cell activity, and intake rate for each group are presented in Table 4. These characteristics did not significantly differ between the two groups, thereby confirming the appropriate allocation of subjects in the active test food and placebo groups. 


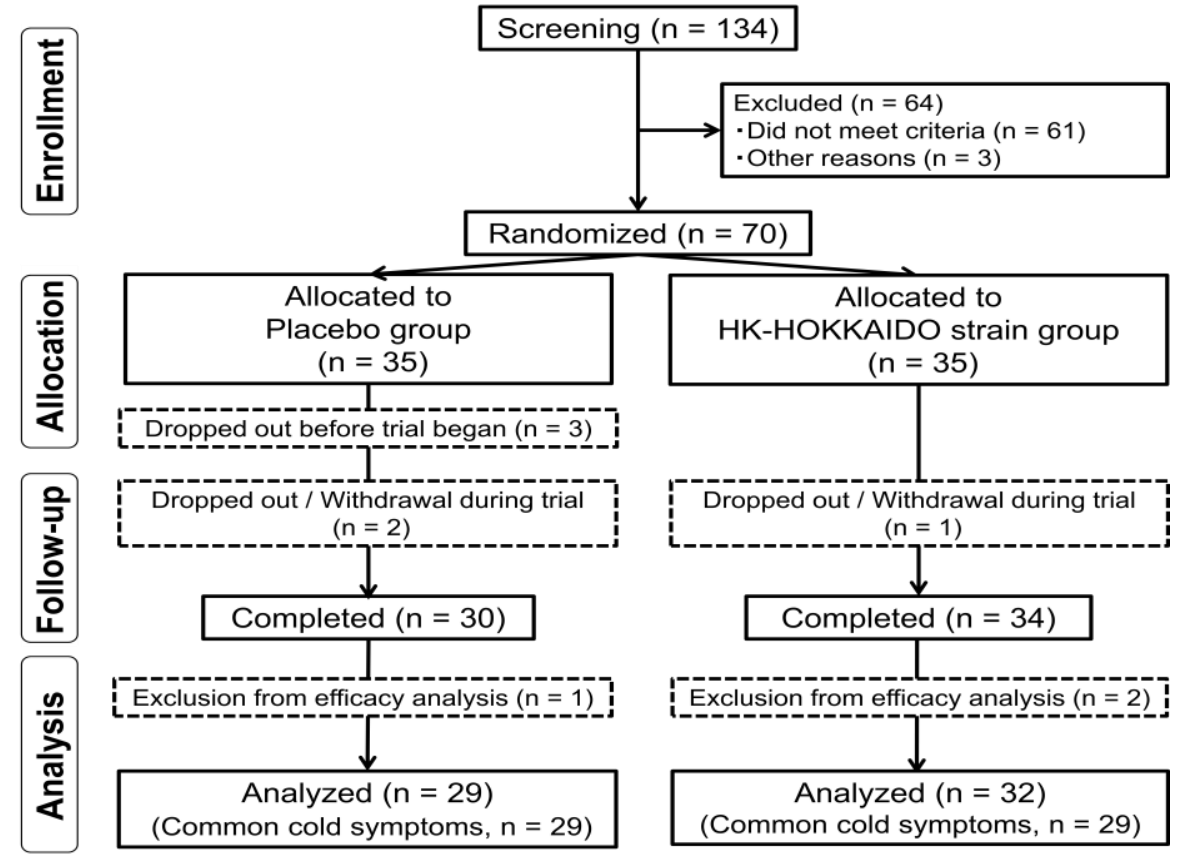

Figure 1: Flowchart of subjects' selection.

Table 4: Characteristics of the subjects and intake rates of the HK-HOKKAIDO strain and placebo groups

\begin{tabular}{llll}
\hline Characteristic & Placebo & HK-HOKKAIDO strain & \multicolumn{1}{c}{$p$} \\
\hline Subjects $(n)$ & 29 & 32 & - \\
Male $(n)$ & 2 & 3 & 1.00 \\
Age $($ years $)$ & $41.8 \pm 5.3$ & $43.9 \pm 4.8$ & 0.11 \\
BMI $\left(\mathrm{kg} / \mathrm{m}^{2}\right)$ & $20.4 \pm 2.6$ & $20.0 \pm 2.4$ & 0.55 \\
NK cell activity $(\%)$ & $50.8 \pm 16.3$ & $52.7 \pm 13.7$ & 0.62 \\
Intake rate $(\%)$ & 98.8 & 99.3 & 0.57 \\
\hline
\end{tabular}

Values are shown as mean \pm standard deviation. Fisher's exact probability test was used for sex, and the Mann-Whitney $U$ test was used for the intake rate. Student's $t$-test was used for the other characteristics. $n$, number of subjects; BMI, body mass index; NK, natural killer

\section{Effect of the HK-HOKKAIDO strain on NK cell activity}

The effects of the HK-HOKKAIDO strain on NK cell activity are summarized in Table 5. There were no significant differences in the effects on the NK cell activity between the HK-HOKKAIDO strain and placebo groups (change in value from baseline to week 8: placebo group, $-4.8 \pm 9.4 \%$; HK-HOKKAIDO strain group, $-4.3 \pm 8.6 \% ; p=0.82$ ).

\section{Effect of the HK-HOKKAIDO strain on immunity markers}

To confirm the effects of the HK-HOKKAIDO strain on immunity markers, changes in IgA, IgG, and IgM levels; neutrophil, lymphocyte, monocyte, eosinophil, and basophil concentrations and neutrophil-lymphocyte ratio; and salivary s-IgA levels were evaluated (Table 5). There were no significant differences in these marker levels between the HK-HOKKAIDO strain and placebo groups (Table 5). 
Table 5: NK cell activity and immunity marker

\begin{tabular}{|c|c|c|c|c|c|}
\hline Variable & & $n$ & Week 0 & $\Delta$ Week 4 & $\Delta$ Week 8 \\
\hline \multirow{3}{*}{ NK cell activity (\%) } & Placebo & 29 & $58.6 \pm 17.7$ & $-4.8 \pm 8.4$ & $-4.8 \pm 9.4$ \\
\hline & Active & 32 & $58.4 \pm 16.9$ & $-2.3 \pm 7.2$ & $-4.3 \pm 8.6$ \\
\hline & $p$ & & 0.97 & 0.21 & 0.82 \\
\hline \multirow{3}{*}{ IgA (mg/dL) } & Placebo & 29 & $201.7 \pm 86.1$ & $1.2 \pm 12.6$ & $-1.7 \pm 13.3$ \\
\hline & Active & 32 & $202.5 \pm 59.2$ & $1.9 \pm 12.1$ & $-1.9 \pm 12.1$ \\
\hline & $p$ & & 0.97 & 0.84 & 0.96 \\
\hline \multirow{3}{*}{$\operatorname{IgG}(\mathrm{mg} / \mathrm{dL})$} & Placebo & 29 & $1,245.2 \pm 194.2$ & $12.6 \pm 73.0$ & $-2.9 \pm 52.7$ \\
\hline & Active & 32 & $1,278.4 \pm 256.6$ & $10.5 \pm 67.6$ & $4.8 \pm 68.4$ \\
\hline & $p$ & & 0.57 & 0.91 & 0.63 \\
\hline \multirow{3}{*}{$\operatorname{IgM}(\mathrm{mg} / \mathrm{dL})$} & Placebo & 29 & $125.2 \pm 49.1$ & $0.2 \pm 10.4$ & $-1.6 \pm 6.6$ \\
\hline & Active & 32 & $127.9 \pm 56.5$ & $-0.4 \pm 8.5$ & $-0.8 \pm 10.8$ \\
\hline & $p$ & & 0.85 & 0.83 & 0.72 \\
\hline \multirow{3}{*}{ Neutrophils (\%) } & Placebo & 29 & $59.5 \pm 10.1$ & $1.2 \pm 7.3$ & $2.7 \pm 6.3$ \\
\hline & Active & 32 & $61.1 \pm 7.8$ & $2.0 \pm 6.1$ & $0.6 \pm 5.7$ \\
\hline & $p$ & & 0.5 & 0.65 & 0.17 \\
\hline \multirow{3}{*}{ Lymphocytes (\%) } & Placebo & 29 & $31.6 \pm 8.3$ & $-0.8 \pm 6.5$ & $-2.5 \pm 5.6$ \\
\hline & Active & 32 & $30.8 \pm 6.6$ & $-2.0 \pm 5.2$ & $-0.8 \pm 4.9$ \\
\hline & $p$ & & 0.68 & 0.43 & 0.21 \\
\hline \multirow{3}{*}{ Monocytes (\%) } & Placebo & 29 & $5.2 \pm 1.5$ & $0.0 \pm 1.1$ & $0.1 \pm 0.8$ \\
\hline & Active & 32 & $5.4 \pm 1.6$ & $0.1 \pm 0.9$ & $0.1 \pm 1.2$ \\
\hline & $p$ & & 0.74 & 0.61 & 0.83 \\
\hline \multirow{3}{*}{ Eosinophils (\%) } & Placebo & 29 & $2.6 \pm 1.6$ & $-0.3 \pm 0.8$ & $-0.2 \pm 0.6$ \\
\hline & Active & 32 & $1.8 \pm 1.2$ & $0.0 \pm 0.7$ & $0.0 \pm 0.8$ \\
\hline & $p$ & & 0.06 & 0.18 & 0.13 \\
\hline \multirow{3}{*}{ Basophils (\%) } & Placebo & 29 & $1.0 \pm 0.6$ & $0.0 \pm 0.5$ & $0.0 \pm 0.6$ \\
\hline & Active & 32 & $0.9 \pm 0.5$ & $-0.1 \pm 0.6$ & $0.0 \pm 0.5$ \\
\hline & $p$ & & 0.37 & 0.65 & 0.98 \\
\hline \multirow{3}{*}{$\begin{array}{l}\text { Neutrophil-lymphocyte } \\
\text { ratio }\end{array}$} & Placebo & 29 & $2.1 \pm 1.1$ & $0.1 \pm 0.8$ & $0.2 \pm 0.9$ \\
\hline & Active & 32 & $2.1 \pm 0.7$ & $0.2 \pm 0.6$ & $0.1 \pm 0.5$ \\
\hline & $p$ & & 0.95 & 0.48 & 0.36 \\
\hline \multirow{3}{*}{ Salivary s- $\operatorname{IgA}(\mu \mathrm{g} / \mathrm{mL})$} & Placebo & 29 & $164.4 \pm 76.2$ & - & $5.6 \pm 79.3$ \\
\hline & Active & 32 & $154.4 \pm 83.5$ & - & $5.4 \pm 68.0$ \\
\hline & $p$ & & 0.63 & - & 0.99 \\
\hline
\end{tabular}

Values are shown as the mean \pm standard deviation. $\Delta$ Week 4 : change in value from baseline to week 4; $\Delta$ Week 8: change in value from baseline to week 8. Student's $t$-test was performed. NK, natural killer; IgA, immunoglobulin A; IgG, immunoglobulin G; IgM, immunoglobulin M; s$\operatorname{IgA}$, secretory IgA 


\section{Effect of the HK-HOKKAIDO strain on the parameters assessed using the VAS}

We examined the effect of the HK-HOKKAIDO strain on defecation and fatigue using the VAS questionnaire. There were no significant differences between the HK-HOKKAIDO strain and placebo groups (data not shown).

\section{Effect of the HK-HOKKAIDO strain on the frequency of common cold symptoms}

We examined the frequency of common cold symptoms in both test groups (Table 6). With regard to fever, chills, and malaise symptoms, from day 0 to day 28 , the frequency of severe cold in the HK-HOKKAIDO strain group was significantly higher than that in the placebo group. However, from day 29 to day 58, the frequency of severe and mild cold in the HK-HOKKAIDO strain group was significantly lower than that in the placebo group. With regard to nasal discharge and nasal congestion, the frequency of no symptoms and severe cold was significantly lower and that of mild cold was significantly higher in the HK-HOKKAIDO strain group than that in the placebo group, from day 0 to day 28. With regard to nasal discharge, coughing and sputum production, the frequency of mild cold in the HK-HOKKAIDO strain group was significantly lower than that in the placebo group from day 29 to day 58.

In addition, we analyzed the number of subjects with cold common symptoms. From day 0 to day 28, no significant difference was observed between both groups; however, from day 29 to day 58 , the number of participants with cold common symptoms in the HK-HOKKAIDO strain group tended to be lower than that in the placebo group (placebo group, 44.8\%; HK-HOKKAIDO strain group, 20.7\%; $p=0.050$; Table 7).

Table 6: Response rate of common cold symptoms

\begin{tabular}{|c|c|c|c|c|c|c|c|}
\hline \multirow[b]{2}{*}{ Variable } & \multirow{2}{*}{$\begin{array}{l}\text { Aggregation } \\
\text { period }\end{array}$} & & \multirow[b]{2}{*}{$n$} & \multicolumn{3}{|c|}{ Response rate $(\%)$} & \multirow[t]{2}{*}{$p$} \\
\hline & & & & $\begin{array}{l}\text { No } \\
\text { symptoms }\end{array}$ & Mild & Severe & \\
\hline \multirow{4}{*}{$\begin{array}{l}\text { Fever } \\
\text { chills }\end{array}$} & \multirow{2}{*}{ From day 0 to day 28} & Placebo & 29 & $97.0^{\#}$ & 2.5 & $0.5^{\#}$ & \multirow{2}{*}{$0.012^{*}$} \\
\hline & & Active & 29 & $94.6^{\#}$ & 3.4 & $2.0^{\#}$ & \\
\hline & \multirow{2}{*}{ From day 29 to day 58} & Placebo & 29 & $95.9^{\#}$ & $3.2^{\#}$ & $0.9^{\#}$ & \multirow{2}{*}{$0.003^{* *}$} \\
\hline & & Active & 29 & $98.4^{\#}$ & $1.6^{\#}$ & $0.0^{\#}$ & \\
\hline \multirow{3}{*}{ Malaise } & \multirow{2}{*}{ From day 0 to day 28} & Placebo & 29 & $94.8^{\#}$ & 4.7 & $0.5^{\#}$ & \multirow{2}{*}{$0.002^{* *}$} \\
\hline & & Active & 29 & $91.7^{\#}$ & 5.8 & $2.5^{\#}$ & \\
\hline & From day 29 to day 58 & Placebo & 29 & $96.6^{\#}$ & $2.8^{\#}$ & $0.6^{\#}$ & $0.002^{* *}$ \\
\hline
\end{tabular}




\begin{tabular}{|c|c|c|c|c|c|c|c|}
\hline \multirow{3}{*}{ Variable } & \multirow{3}{*}{$\begin{array}{l}\text { Aggregation } \\
\text { period }\end{array}$} & & \multirow[b]{2}{*}{$n$} & \multicolumn{3}{|c|}{ Response rate $(\%)$} & \multirow[t]{2}{*}{$p$} \\
\hline & & & & $\begin{array}{l}\text { No } \\
\text { symptoms }\end{array}$ & Mild & Severe & \\
\hline & & Active & 29 & $99.0^{\#}$ & $1.0^{\#}$ & $0.0^{\#}$ & \\
\hline \multirow{4}{*}{ Coughing } & \multirow{2}{*}{ From day 0 to day 28} & Placebo & 29 & 90.3 & 7.6 & 2.1 & \multirow{2}{*}{0.11} \\
\hline & & Active & 29 & 87.2 & 10.6 & 2.2 & \\
\hline & \multirow{2}{*}{ From day 29 to day 58} & Placebo & 29 & $92.0^{\#}$ & $7.5^{\#}$ & 0.5 & \multirow{2}{*}{$0.022^{*}$} \\
\hline & & Active & 29 & $95.3^{\#}$ & $4.3^{\#}$ & 0.4 & \\
\hline \multirow{4}{*}{$\begin{array}{l}\text { Sputum } \\
\text { production }\end{array}$} & \multirow{2}{*}{ From day 0 to day 28} & Placebo & 29 & 89.3 & 9.2 & 1.5 & \multirow{2}{*}{0.65} \\
\hline & & Active & 29 & 88.3 & 10.5 & 1.2 & \\
\hline & \multirow{2}{*}{ From day 29 to day 58} & Placebo & 29 & $92.2^{\#}$ & $7.5^{\#}$ & 0.2 & \multirow{2}{*}{$0.003^{* *}$} \\
\hline & & Active & 29 & $95.9^{\#}$ & $3.7^{\#}$ & 0.4 & \\
\hline \multirow{4}{*}{ Sore throat } & \multirow{2}{*}{ From day 0 to day 28} & Placebo & 29 & 91.9 & 6.8 & 1.4 & \multirow{2}{*}{0.089} \\
\hline & & Active & 29 & 89.2 & 9.7 & 1.1 & \\
\hline & \multirow{2}{*}{ From day 29 to day 58} & Placebo & 29 & 95.2 & 4.6 & 0.2 & \multirow{2}{*}{0.12} \\
\hline & & Active & 29 & 97.2 & 2.7 & 0.1 & \\
\hline \multirow{4}{*}{$\begin{array}{l}\text { Nasal } \\
\text { discharge }\end{array}$} & \multirow{2}{*}{ From day 0 to day 28} & Placebo & 29 & $81.5^{\#}$ & $16.5^{\#}$ & $2.0^{\#}$ & \multirow{2}{*}{$<0.001^{* *}$} \\
\hline & & Active & 29 & $75.6^{\#}$ & $23.8^{\#}$ & $0.6^{\#}$ & \\
\hline & \multirow{2}{*}{ From day 29 to day 58} & Placebo & 29 & $83.1^{\#}$ & $16.4^{\#}$ & 0.5 & \multirow{2}{*}{$0.025^{*}$} \\
\hline & & Active & 29 & $87.8^{\#}$ & $11.9^{\#}$ & 0.2 & \\
\hline \multirow{4}{*}{$\begin{array}{l}\text { Nasal } \\
\text { congestion }\end{array}$} & \multirow{2}{*}{ From day 0 to day 28} & Placebo & 29 & $92.2^{\#}$ & $6.2^{\#}$ & $1.6^{\#}$ & \multirow{2}{*}{$<0.001^{* * *}$} \\
\hline & & Active & 29 & $87.2^{\#}$ & $12.6^{\#}$ & $0.2^{\#}$ & \\
\hline & \multirow{2}{*}{ From day 29 to day 58} & Placebo & 29 & 94.5 & 5.4 & 0.1 & \multirow{2}{*}{0.60} \\
\hline & & Active & 29 & 94.5 & 5.5 & 0.0 & \\
\hline \multirow{4}{*}{ Sneezing } & From dluy 0 to dow 28 & Placebo & 29 & 93.1 & 6.9 & 0.0 & 060 \\
\hline & & Active & 29 & 92.9 & 7.0 & 0.1 & \\
\hline & & Placebo & 29 & 94.2 & 5.8 & 0.0 & \\
\hline & From day 29 to day 58 & Active & 29 & 95.1 & 4.7 & 0.2 & 0.23 \\
\hline
\end{tabular}

The frequency of the common cold symptoms was analyzed using the chi-squared test. If significant for the chi-squared test, the adjusted residual was calculated. Chi-squared test: $p<$ $0.05^{*}, p<0.001^{* *}$, and adjusted residual: $\geq \pm 1.96^{\#}$. 
Table 7: Number of subjects with common cold symptoms

\begin{tabular}{lllll} 
& & $n$ & $\%$ & $p$ \\
\hline \multirow{2}{*}{ From 0 to 28 day } & Placebo & 12 & 41.3 & \\
& Active & 12 & 41.3 & 1.000 \\
\hline From 29 to 58 & Placebo & 13 & 44.8 & \\
day & Active & 6 & 20.7 & 0.050 \\
\hline
\end{tabular}

The number of subjects with common cold symptoms was analyzed using the chi-squared test.

\section{Safety}

For the safety analysis of the HK-HOKKAIDO strain, the body composition (BFR and BMI), vital signs [systolic blood pressure (SBP), diastolic blood pressure (DBP), and body temperature], complete blood counts (WBC, RBC, Hb, Ht, and Plt), liver function (AST, ALT, $\gamma$-GTP, ALP, and LDH), renal function (BUN, CRE, and UA), lipid profile (TC, LDL-C, HDL-C, and TG), and blood glucose profile (FPG and $\mathrm{HbA}_{1 \mathrm{c}}$ ) were evaluated (Table 8). Minimal changes (Table 8) and minimal adverse effects (variation in the clinical data and clinical observation) were observed in each group. These changes were within the normal range, and adverse effects disappeared within a few days after the intake was initiated during the study period. Therefore, the principal investigator judged that none of the adverse events were related to the intake of the test food.

Table 8: Body composition, vital signs, complete blood counts, liver function, renal function, lipid profile, and blood glucose profile

\begin{tabular}{llllll}
\hline Variable & & $\boldsymbol{n}$ & Week 0 & $\Delta$ Week 4 & $\Delta$ Week 8 \\
\hline \multirow{2}{*}{ BFR $(\%)$} & Placebo & 32 & $27.2 \pm 6.0$ & $0.2 \pm 1.1$ & $0.2 \pm 1.2$ \\
& Active & 35 & $26.0 \pm 6.2$ & $0.1 \pm 1.5$ & $0.7 \pm 1.5$ \\
\hline \multirow{2}{*}{ BMI $\left(\mathrm{kg} / \mathrm{m}^{2}\right)$} & Placebo & 32 & $20.4 \pm 3.2$ & $0.1 \pm 0.3$ & $0.1 \pm 0.4$ \\
& Active & 35 & $20.0 \pm 2.5$ & $0.0 \pm 0.3$ & $0.1 \pm 0.3$ \\
\hline \multirow{2}{*}{$\mathrm{SBP}(\mathrm{mmHg})$} & Placebo & 32 & $110.2 \pm 19.0$ & $0.9 \pm 8.8$ & $4.1 \pm 8.9$ \\
& Active & 35 & $109.0 \pm 11.1$ & $2.3 \pm 9.1$ & $2.0 \pm 8.4$ \\
\hline \multirow{2}{*}{ DBP $(\mathrm{mmHg})$} & Placebo & 32 & $71.8 \pm 10.1$ & $0.9 \pm 4.9$ & $0.4 \pm 4.9$ \\
\hline Body temperature & Active & 35 & $70.0 \pm 8.7$ & $0.8 \pm 6.1$ & $0.8 \pm 6.8$ \\
$\left({ }^{\circ} \mathrm{C}\right)$ & Placebo & 32 & $36.4 \pm 0.5$ & $-0.1 \pm 0.5$ & $0.0 \pm 0.4$ \\
\hline & Active & 35 & $36.3 \pm 0.4$ & $-0.1 \pm 0.3$ & $0.0 \pm 0.4$ \\
\hline
\end{tabular}




\begin{tabular}{|c|c|c|c|c|c|}
\hline Variable & & $n$ & Week 0 & $\Delta$ Week 4 & $\Delta$ Week 8 \\
\hline \multirow{2}{*}{$\mathrm{WBC}\left(\times 10^{3} / \mu \mathrm{L}\right)$} & Placebo & 32 & $5.3 \pm 1.7$ & $0.3 \pm 1.3$ & $0.2 \pm 1.2$ \\
\hline & Active & 35 & $5.1 \pm 1.4$ & $0.2 \pm 0.8$ & $0.0 \pm 0.8$ \\
\hline \multirow{2}{*}{$\mathrm{RBC}\left(\times 10^{4} / \mu \mathrm{L}\right)$} & Placebo & 32 & $449.2 \pm 45.5$ & $8.8 \pm 27.4$ & $6.5 \pm 18.9$ \\
\hline & Active & 35 & $445.9 \pm 33.2$ & $-1.4 \pm 20.2$ & $3.9 \pm 23.4$ \\
\hline \multirow{2}{*}{$\mathrm{Hb}(\mathrm{g} / \mathrm{dL})$} & Placebo & 32 & $13.0 \pm 1.3$ & $0.2 \pm 0.6$ & $0.3 \pm 0.5$ \\
\hline & Active & 35 & $13.3 \pm 1.1$ & $0.0 \pm 0.6$ & $0.2 \pm 0.7$ \\
\hline \multirow{2}{*}{$\mathrm{Ht}(\%)$} & Placebo & 32 & $40.4 \pm 3.6$ & $0.3 \pm 2.1$ & $0.5 \pm 1.6$ \\
\hline & Active & 35 & $40.6 \pm 3.1$ & $0.0 \pm 1.8$ & $0.6 \pm 2.2$ \\
\hline \multirow{2}{*}{ Plt $\left(\times 10^{4} / \mu \mathrm{L}\right)$} & Placebo & 32 & $27.7 \pm 5.8$ & $1.7 \pm 2.7$ & $0.6 \pm 2.9$ \\
\hline & Active & 35 & $26.2 \pm 4.7$ & $0.3 \pm 2.1$ & $0.0 \pm 2.3$ \\
\hline \multirow{2}{*}{ AST (U/L) } & Placebo & 32 & $19.4 \pm 6.4$ & $0.0 \pm 3.4$ & $1.2 \pm 9.1$ \\
\hline & Active & 35 & $20.3 \pm 4.7$ & $0.2 \pm 3.1$ & $0.6 \pm 3.5$ \\
\hline \multirow{2}{*}{ ALT (U/L) } & Placebo & 32 & $16.9 \pm 12.5$ & $-0.1 \pm 5.7$ & $6.5 \pm 34.7$ \\
\hline & Active & 35 & $16.4 \pm 7.0$ & $0.3 \pm 5.6$ & $1.3 \pm 5.7$ \\
\hline \multirow{2}{*}{$\gamma$-GTP (U/L) } & Placebo & 32 & $18.0 \pm 7.8$ & $1.0 \pm 3.8$ & $5.8 \pm 33.4$ \\
\hline & Active & 35 & $26.8 \pm 41.0$ & $3.7 \pm 20.8$ & $0.3 \pm 7.3$ \\
\hline \multirow{2}{*}{ ALP (U/L) } & Placebo & 32 & $169.7 \pm 49.2$ & $2.3 \pm 16.1$ & $10.8 \pm 35.0$ \\
\hline & Active & 35 & $166.8 \pm 34.5$ & $8.0 \pm 17.1$ & $8.0 \pm 14.6$ \\
\hline \multirow{2}{*}{ LDH (U/L) } & Placebo & 32 & $160.3 \pm 19.6$ & $2.4 \pm 10.0$ & $4.9 \pm 10.3$ \\
\hline & Active & 35 & $167.9 \pm 26.7$ & $0.5 \pm 11.6$ & $1.4 \pm 11.4$ \\
\hline \multirow{2}{*}{ BUN (mg/dL) } & Placebo & 32 & $11.8 \pm 4.1$ & $0.5 \pm 2.5$ & $-0.2 \pm 2.1$ \\
\hline & Active & 35 & $12.2 \pm 3.6$ & $-0.4 \pm 2.1$ & $-0.2 \pm 2.5$ \\
\hline \multirow{2}{*}{ CRE (mg/dL) } & Placebo & 32 & $0.72 \pm 0.07$ & $-0.01 \pm 0.04$ & $-0.01 \pm 0.04$ \\
\hline & Active & 35 & $0.69 \pm 0.11$ & $-0.01 \pm 0.04$ & $0.00 \pm 0.04$ \\
\hline \multirow{2}{*}{$\mathrm{UA}(\mathrm{mg} / \mathrm{dL})$} & Placebo & 32 & $4.2 \pm 1.1$ & $0.0 \pm 0.4$ & $-0.1 \pm 0.5$ \\
\hline & Active & 35 & $4.1 \pm 0.9$ & $0.0 \pm 0.5$ & $0.1 \pm 0.6$ \\
\hline \multirow{2}{*}{$\mathrm{TC}(\mathrm{mg} / \mathrm{dL})$} & Placebo & 32 & $207.5 \pm 34.0$ & $6.2 \pm 13.3$ & $6.0 \pm 17.6$ \\
\hline & Active & 35 & $204.2 \pm 31.5$ & $-1.2 \pm 21.8$ & $7.0 \pm 16.8$ \\
\hline \multirow{2}{*}{ LDL-C (mg/dL) } & Placebo & 32 & $119.06 \pm 35.76$ & $4.84 \pm 12.47$ & $1.87 \pm 14.56$ \\
\hline & Active & 35 & $111.63 \pm 27.96$ & $1.34 \pm 15.30$ & $2.65 \pm 13.78$ \\
\hline HDL-C (mg/dL) & Placebo & 32 & $74.8 \pm 15.9$ & $2.9 \pm 5.1$ & $4.7 \pm 6.6$ \\
\hline
\end{tabular}




\begin{tabular}{llllll}
\hline Variable & & $\boldsymbol{n}$ & Week 0 & $\Delta$ Week 4 & $\Delta$ Week 8 \\
\hline \multirow{2}{*}{$\mathrm{TG}(\mathrm{mg} / \mathrm{dL})$} & Active & 35 & $81.0 \pm 21.3$ & $0.3 \pm 9.0$ & $3.9 \pm 9.0$ \\
\hline \multirow{2}{*}{$\mathrm{FPG}(\mathrm{mg} / \mathrm{dL})$} & Placebo & 32 & $73.9 \pm 45.6$ & $4.3 \pm 22.3$ & $-0.3 \pm 18.4$ \\
& Active & 35 & $69.7 \pm 35.8$ & $3.6 \pm 23.4$ & $1.0 \pm 25.8$ \\
\hline \multirow{2}{*}{$\mathrm{HbA}_{1 \mathrm{c}}(\%)$} & Placebo & 32 & $83.5 \pm 5.7$ & $0.6 \pm 5.4$ & $0.2 \pm 3.9$ \\
& Active & 35 & $85.4 \pm 5.0$ & $0.3 \pm 4.2$ & $-0.4 \pm 4.4$ \\
\hline
\end{tabular}

Values are shown as the mean \pm standard deviation. $\Delta$ Week 4 : change in value from baseline to week 4 ; $\Delta$ Week 8: change in value from baseline to week 8. Student's $t$-test was performed.

BFR, body fat rate; BMI, body mass index; SBP, systolic blood pressure; DBP, diastolic blood pressure; WBC, white blood cell; RBC, red blood cell; Hb, hemoglobin; Ht, hematocrit; Plt, platelet; AST, aspartate aminotransferase; ALT, alanine aminotransferase; $\gamma$-GTP, $\gamma$-glutamyltranspeptidase; ALP, alkaline phosphatase; LDH, lactate dehydrogenase; BUN, blood urea nitrogen; CRE, creatinine; UA, uric acid; TC, total cholesterol; LDL-C, low-density lipoprotein cholesterol; HDL-C, high-density lipoprotein cholesterol; $\mathrm{TG}$, triglyceride; FPG, fasting plasma glucose; $\mathrm{HbA}_{1 c}$, hemoglobin $\mathrm{A}_{1 \mathrm{c}}$.

\section{DISCUSSION}

In the present clinical trial, we assessed the effect of the daily intake of the HK-HOKKAIDO strain for 8 weeks on immunocompetence in subjects with low NK cell activity. We observed that ingesting the HK-HOKKAIDO strain reduces the frequency and severity of common cold symptoms in these subjects.

The primary outcome - a change in the NK cell activity-was not significantly different between the HK-HOKKAIDO strain and placebo groups in this trial. The administration of heattreated L. plantarum to immunodeficient mice has reportedly increased the NK cell activity and NK cell activity-related cytokines (TNF- $\alpha$, IL-2, and IL-12) [22]. Moreover, in a clinical trial involving 200 subjects 60 years of age, daily intake of heat-treated Lactobacillus paracasei ssp. paracasei, Bifidobacterium animalis ssp. lactis, and heat-treated L. plantarum for 12 weeks significantly increased the NK cell activity, IFN- $\gamma$, and IgG levels in the test food group compared with the placebo food group [23]. The data of this clinical trial were obtained during winter (from December to February). Previous in vivo experiments reported that NK cell activity reduced under the cold-stress [24-26]. For exploratory analysis, in subjects with NK cell activity between $60 \%$ and $70 \%$, we found that the NK cell activity in the placebo group was significantly decreased 
compared with that in the HK-HOKKAIDO group [change in NK cell activity from baseline to week 8: placebo group $(\mathrm{n}=15),-10.16 \% \pm 8.88 \%$; HK-HOKKAIDO strain group $(\mathrm{n}=17)$, $-0.80 \% \pm 7.68 \% ; p=0.003]$. Among subjects with NK cell activity of $<60 \%$, no differences were observed in the HK-HOKKAIDO strain and placebo groups. These results suggested that the HKHOKKAIDO strain suppressed the decrease of NK cell activity under cold stress, although our results were limited.

With regard to the secondary endpoint, the frequency and severity of common cold symptoms from day 29 to day 58 significantly declined in the HK-HOKKAIDO strain group compared with that in the placebo group. Therefore, our results suggest that the daily intake of the HKHOKKAIDO strain for 8 weeks reduces the risk of common cold symptoms in participants with low NK cell activity. However, this effect of the HK-HOKKAIDO strain was not observed until 4 weeks; rather, from day 0 to day 28 , the frequency of common cold symptoms in the HKHOKKAIDO group was worse than that in the placebo group. Comprehensively, almost all subjects in HK-HOKKAIDO strain group reported common cold symptoms from day 0 to day 7 . Previous studies have suggested that for demonstrating the effect of probiotics, the intervention period should be $>2$ weeks [27-29]. Accordingly, it is suggested that at least 4 weeks of intake is necessary for observing the immunostimulatory effect of the HK-HOKKAIDO strain. The viral cold is contagious and can spread through cough and runny nose, and this infection can become severe in infants and the elderly. Therefore, preventing the spread of infection and strengthening the body's immune system against infections are important [30,31]. The effects of probiotics on the common cold symptoms have been reported in previous clinical trials [20,32]. Our findings suggest that the daily intake of the HK-HOKKAIDO strain as a supplement has a preventive effect on common cold.

In terms of the immunoglobulin ( $\operatorname{IgA}, \operatorname{IgG}$, and $\operatorname{IgM})$ and leukocyte fractions, no significant difference was observed between the HK-HOKKAIDO strain and placebo groups, and there was no association between these variables and the frequency of common cold symptoms. In addition, no significant difference was observed in the salivary s-IgA levels between both groups. Viruses infect the epithelial cells present on the surface of the upper respiratory tract, and mucosal immunity is the key factor for the prevention of this infection [33]. s-IgA is an important factor in mucosal immunity and is produced in the mucosa-associated lymphoid tissue in Peyer's patch cells [34]. In vitro studies on plant lactic acid bacteria have shown that s-IgA secretion was promoted from Peyer's patch cells, whereas in vivo experiments have shown that plant lactic acid bacteria was associated with prolonged survival following influenza virus infection $[35,36]$. In the present 
study, a subgroup analysis was performed using the initial value of s-IgA; however, in participants with low salivary s-IgA, the consumption of the HK-HOKKAIDO strain resulted in no difference in evaluation variables, including common cold symptoms. Therefore, the objective evaluation variables related to the immune function should be examined in the future.

Furthermore, no significant differences were observed between the HK-HOKKAIDO strain and placebo groups in the VAS questionnaire assessing the gastrointestinal tract condition and fatigue. Several studies have demonstrated the relationship between the intestinal flora and immune function [37-39]. In the future, the effects of the HK-HOKKAIDO strain on the intestinal flora should be investigated, and the association between the intestinal flora and immunocompetence should be elucidated.

In the present clinical trial, no side effects or severe adverse events were observed during physical and blood examinations or in the medical interviews. These results confirm the safety of the 8-week intake of $5 \times 10^{10} \mathrm{CFU}$ of the HK-HOKKAIDO strain daily as a health supplement.

This study had a few limitations. First, the effects of the consumption of the HK-HOKKAIDO strain were assessed only for 8 weeks; therefore, the effects of its long-term consumption should be investigated. Second, no improvement was observed in the objective evaluation variables owing to the consumption of the HK-HOKKAIDO strain in this trial. Therefore, the objective evaluation variables related to the immune function requires further investigation in the future. Third, the mechanism of action of the HK-HOKKAIDO strain in reducing the severity of the cold symptoms remains unknown and should be elucidated at the molecular level.

\section{CONCLUSIONS}

In the present study, we showed that the daily intake of the HK-HOKKAIDO strain for 8 weeks reduced the severity and frequency of the common cold symptoms in patients with low NK cell activity. Additionally, we confirmed the safety of the consumption of the HK-HOKKAIDO strain over a period of 8 weeks. The findings of this 8 -week randomized, double-blind, placebocontrolled, parallel-group comparative trial support the use of the HK-HOKKAIDO strain as a functional food with health benefits for individuals with low NK cell activity.

List of Abbreviations: ALT, alanine aminotransferase; ALP, alkaline phosphatase; AST, aspartate aminotransferase; BFR, body fat rate; BMI, body mass index; BUN, blood urea nitrogen; CRE, creatinine; DBP, diastolic blood pressure; $\gamma$-GTP, $\gamma$-glutamyltranspeptidase; Hb, hemoglobin; $\mathrm{HbA}_{1 c}$, hemoglobin $\mathrm{A}_{1 \mathrm{c}}$; HDL-C, high-density lipoprotein cholesterol; $\mathrm{Ht}$, hematocrit; IgA, 
immunoglobulin A; IgG, immunoglobulin $\mathrm{G}$; IgM, immunoglobulin $\mathrm{M}$; $\mathrm{LDH}$, lactate dehydrogenase; LDL-C, low-density lipoprotein cholesterol; NK, natural killer; Plt, platelet; RBC, red blood cell; SBP, systolic blood pressure; s-IgA, secretory IgA; TC, total cholesterol; TG, triglyceride; UA, uric acid; WBC, white blood cell; VAS, visual analog scale.

Competing Interests: This study was conducted with research funds under contract with the Northern Advancement Center for Science \& Technology.

Author Contributions: M. Nishimura, M. Sugawara, M. Kudo, and J. Nishihira designed the clinical trial. M. Sugawara, M. Kudo and R. Nakagawa designed the test food. J. Nishihira conducted the research. A. Haseda and M. Nishimura conducted the statistical analysis. A. Haseda, M. Nishimura, and J. Nishihira wrote the manuscript. All authors take responsibility for the final content of the manuscript.

Acknowledgments and Funding: We would like to thank the members of the Hokkaido Information University, Health Information Science Research Center (Y. Anzai, Y. Fukuda, M. Hatakeyama, M. Ito, H. Katsuyama-Kagami, S. Kamo, A. Miyao, M. Ohshima, T. Saito, M. Sasaki, K. Sato, N. Shima, M. Teramoto, and N. Yamazaki) for their technical assistance with the clinical trial. This study was conducted with research funds under contract with the Northern Advancement Center for Science \& Technology. The Northern Advancement Center for Science \& Technology was supported by a grant from the Research Project on the Development of Functional Foods Produced in Hokkaido (Hokkaido, Japan). The authors would like to thank Enago for the English language review.

\section{REFERENCES}

1. Eckburg PB, Bik EM, Bernstein CN, Purdom E, Dethlefsen L, Sargent M, Gill SR, et al.: Diversity of the human intestinal microbial flora. Science. 2005, 308: 1635-1638.

2. Reid G, Sanders ME, Gaskins HR, Gibson GR, Mercenier A, Rastall R, Roberfroid M, et al.: New scientific paradigms for probiotics and prebiotics. J Clin Gastroenterol. 2003, 37: 105118.

3. Kellow NJ, Coughlan MT, Reid CM: Metabolic benefits of dietary prebiotics in human subjects: a systematic review of randomised controlled trials. Br J Nutr. 2014, 111: 1147-1161.

4. Hills RD, Jr., Pontefract BA, Mishcon HR, Black CA, Sutton SC, Theberge CR: Gut microbiome: profound implications for diet and disease. Nutrients. 2019, 11.

5. Morikawa Y, Kitaoka-Higashiguchi K, Tanimoto C, Hayashi M, Oketani R, Miura K, Nishijo 
M, et al.: A cross-sectional study on the relationship of job stress with natural killer cell activity and natural killer cell subsets among healthy nurses. J Occup Health. 2005, 47: 378383.

6. Kawamura N, Kim Y, Asukai N: Suppression of cellular immunity in men with a past history of posttraumatic stress disorder. Am J Psychiatry. 2001, 158: 484-486.

7. Morimoto K, Takeshita T, Nanno M, Tokudome S, Nakayama K: Modulation of natural killer cell activity by supplementation of fermented milk containing Lactobacillus casei in habitual smokers. Prev Med. 2005, 40: 589-594.

8. O'Shea D, Cawood TJ, O'Farrelly C, Lynch L: Natural killer cells in obesity: impaired function and increased susceptibility to the effects of cigarette smoke. PLoS One. 2010, 5: e8660.

9. Romero-Perez GA, Egashira M, Harada Y, Tsuruta T, Oda Y, Ueda F, Tsukahara T, et al.: Orally administered Salacia reticulata extract reduces H1N1 influenza clinical symptoms in murine lung tissues putatively due to enhanced natural killer cell activity.. Front Immunol. 2016, 7: 115.

10. Zhou K, Wang J, Li A, Zhao W, Wang D, Zhang W, Yan J, et al.: Swift and strong NK cell responses protect 129 mice against high-dose influenza virus infection. J Immunol. 2016, 196: 1842-1854.

11. Kamei M, Nishimura H, Takahashi T, Takahashi N, Inokuchi K, Mato T, Takahashi K: Antiinfluenza virus effects of cocoa. J Sci Food Agric. 2016, 96: 1150-1158.

12. Olivares M, Paz Diaz-Ropero M, Gomez N, Sierra S, Lara-Villoslada F, Martin R, Miguel Rodriguez J, et al.: Dietary deprivation of fermented foods causes a fall in innate immune response. Lactic acid bacteria can counteract the immunological effect of this deprivation. J Dairy Res. 2006, 73: 492-498.

13. Nova E, Warnberg J, Gomez-Martinez S, Diaz LE, Romeo J, Marcos A: Immunomodulatory effects of probiotics in different stages of life. Br J Nutr. 2007, 98 Suppl 1: S90-95.

14. Adlerberth I, Ahrne S, Johansson ML, Molin G, Hanson LA, Wold AE: A mannose-specific adherence mechanism in Lactobacillus plantarum conferring binding to the human colonic cell line HT-29. Appl Environ Microbiol. 1996, 62: 2244-2251.

15. Murosaki S, Yamamoto Y, Ito K, Inokuchi T, Kusaka H, Ikeda H, Yoshikai Y: Heat-killed Lactobacillus plantarum L-137 suppresses naturally fed antigen-specific IgE production by stimulation of IL-12 production in mice. J Allergy Clin Immunol. 1998, 102: 57-64.

16. Okada S: The world of plant origin lactic acid bacteria. Japanese Journal of Lactic Acid Bacteria 2002, 13: 23-36.

17. Nakagawa R, Yabuuchi H, Yasokawa D, Yasokawa D, Nagashima K, Nagashima K: Fermentation of soybean milk with Lactobacillus plantarum HOKKAIDO and its health function. J Jpn Soc Food Sci. 2005, 52: 140-143.

18. Nakagawa R: Development of food having functionality using plant origin lactic acid bacteria 
(HOKKAIDO Strain) (in Japanese). The Food industry. 2009, 52: 32-40.

19. Nishimura M, Ohkawara T, Tetsuka K, Kawasaki Y, Nakagawa R, Satoh H, Sato Y, et al.: Effects of yogurt containing Lactobacillus plantarum HOKKAIDO on immune function and stress markers. J Tradit Complement Med. 2016, 6: 275-280.

20. Berggren A, Lazou Ahren I, Larsson N, Onning G: Randomised, double-blind and placebocontrolled study using new probiotic lactobacilli for strengthening the body immune defence against viral infections. Eur J Nutr. 2011, 50: 203-210.

21. The Japanese Society of Chemotherapy: The criteria for evaluation of adverse reactions and clinical laboratory abnormalities in clinical trials with antimicrobial agents. Chemotherapy. 1991, 39: 687-689.

22. Moon PD, Lee JS, Kim HY, Han NR, Kang I, Kim HM, Jeong HJ: Heat-treated Lactobacillus plantarum increases the immune responses through activation of natural killer cells and macrophages on in vivo and in vitro models. J Med Microbiol. 2019, 68: 467-474.

23. Lee A, Lee YJ, Yoo HJ, Kim M, Chang Y, Lee DS, Lee JH: Consumption of dairy yogurt containing Lactobacillus paracasei ssp. paracasei, Bifidobacterium animalis ssp. lactis and Heat-Treated Lactobacillus plantarum Improves Immune Function Including Natural Killer Cell Activity. Nutrients. 2017, 9.

24. Hu GZ, Yang SJ, Hu WX, Wen Z, He D, Zeng LF, Xiang Q, et al.: Effect of cold stress on immunity in rats. Exp Ther Med. 2016, 11: 33-42.

25. Jiang XH, Guo SY, Xu S: [Cold stress induces the suppression of splenic NK cell activity and the c-fos expression in rat brain]. Zhongguo Ying Yong Sheng Li Xue Za Zhi. 2002, 18: 313316.

26. Makino T, Kato K, Mizukami H: Processed aconite root prevents cold-stress-induced hypothermia and immuno-suppression in mice. Biol Pharm Bull. 2009, 32: 1741-1748.

27. Komano Y, Shimada K, Naito H, Fukao K, Ishihara Y, Fujii T, Kokubo T, et al.: Efficacy of heat-killed Lactococcus lactis JCM 5805 on immunity and fatigue during consecutive high intensity exercise in male athletes: a randomized, placebo-controlled, double-blinded trial. J Int Soc Sports Nutr. 2018, 15: 39.

28. Miyazawa K, Kawase M, Kubota A, Yoda K, Harata G, Hosoda M, He F: Heat-killed Lactobacillus gasseri can enhance immunity in the elderly in a double-blind, placebocontrolled clinical study. Benef Microbes. 2015, 6: 441-449.

29. Ciprandi G, Vizzaccaro A, Cirillo I, Tosca MA: Bacillus clausii exerts immuno-modulatory activity in allergic subjects: a pilot study. Eur Ann Allergy Clin Immunol. 2005, 37: 129-134.

30. Heikkinen T, Jarvinen A: The common cold. Lancet. 2003, 361: 51-59.

31. Fashner J, Ericson K, Werner S: Treatment of the common cold in children and adults. Am Fam Physician. 2012, 86: 153-159.

32. Murata M, Kondo J, Iwabuchi N, Takahashi S, Yamauchi K, Abe F, Miura K: Effects of paraprobiotic Lactobacillus paracasei MCC1849 supplementation on symptoms of the 
common cold and mood states in healthy adults. Benef Microbes. 2018, 10.3920/BM2017.0197: 1-10.

33. van der Waaij LA, Limburg PC, Mesander G, van der Waaij D: In vivo IgA coating of anaerobic bacteria in human faeces. Gut. 1996, 38: 348-354.

34. Brandtzaeg P, Berstad AE, Farstad IN, Haraldsen G, Helgeland L, Jahnsen FL, Johansen FE, et al.: Mucosal immunity--a major adaptive defence mechanism. Behring Inst Mitt. 1997: 123.

35. Kikuchi Y, Yoshida H, Ogita T, Okita K, Fukudome S, Suzuki T, Tanabe S: In vivo dose response and in vitro mechanistic analysis of enhanced immunoglobulin A production by Lactobacillus plantarum AYA. Biosci Microbiota Food Health. 2015, 34: 53-58.

36. Kikuchi Y, Kunitoh-Asari A, Hayakawa K, Imai S, Kasuya K, Abe K, Adachi Y, et al.: Oral administration of Lactobacillus plantarum strain AYA enhances IgA secretion and provides survival protection against influenza virus infection in mice. PLoS One. 2014, 9: e86416.

37. Felix KM, Tahsin S, Wu HJ: Host-microbiota interplay in mediating immune disorders. Ann N Y Acad Sci. 2018, 1417: 57-70.

38. Caso JR, Balanza-Martinez V, Palomo T, Garcia-Bueno B: The microbiota and gut-brain axis: contributions to the immunopathogenesis of schizophrenia. Curr Pharm Des. 2016, 22: 61226133.

39. Shanahan F: The colonic microflora and probiotic therapy in health and disease. Curr Opin Gastroenterol. 2011, 27: 61-65. 